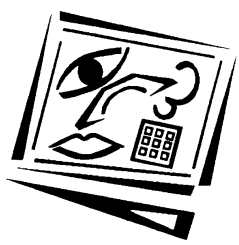

\title{
Reconciling university teacher beliefs to create learning designs for LMS environments
}

\author{
Caroline Steel \\ The University of Queensland
}

\begin{abstract}
Learning management systems (LMS) serve as the primary online technology for student learning in many universities. Although they are only one 'solution', they are often regarded as all encompassing. How university teachers reconcile their beliefs about such technologies with their pedagogical beliefs remains a relatively unexplored area. This study draws on three cases from various disciplines to uncover faculty beliefs about the roles, affordances and limitations of these technologies and how each teacher adapted these to their learning designs within an LMS environment. The overall aim is to reveal the relationship between teacher beliefs and learning designs for web technologies such as LMS. This research contributes to the conceptual understandings that underpin faculty teacher development for technology integration. It provides insightful accounts of the kinds of teacher beliefs that underlie effective learning designs for quite large classes. The resultant stories themselves hold great potential to promote reflection and discourse on the use of technologies in university teaching.
\end{abstract}

\section{Introduction}

Many major studies have investigated the way that university teacher belief systems influence teaching practices and the intended teaching and learning outcomes (Gow \& Kember, 1993; Hativa \& Goodyear, 2002; Kane, Sandretto \& Heath, 2002; Kember, 1997; Samuelowicz \& Bain, 1992). The influence of teacher beliefs naturally extends to our technology teaching practices also (Bain, McNaught, Lueckenhausen \& Mills, 1998; Ertmer, Ottenbreit-Leftwich \& York, 2006-2007; Reeves \& Reeves, 1997). Since the early 2000 's, learning management systems (LMS) have become a standard 'one size fits all' technology 'solution' for online learning and teaching at most universities. While these systems have been purchased with unprecedented enthusiasm, they have not been embraced quite as eagerly by university teachers.

Technology adoption is a complex matter. Even if teachers are confident and proficient in the use of technologies, this does not mean that they believe it is a valuable tool when used for educational purposes. In fact, in terms of technology uptake, teacher beliefs about the value of technology use are a significant factor in predicting usage (Mahdizadeh, Biemans \& Mulder, 2008; Miller et al., 2003). Teachers are more likely to integrate technologies if they can identify how they can support their pedagogical beliefs (Veen, 1993; Zhao \& Frank, 2003). To gain a better understanding of teacher use or non-use of technology, teachers' internal beliefs about learning and teaching must be referenced (Zhou \& Xu, 2007). How university teachers reconcile their beliefs about LMS technologies with their pedagogical beliefs is an area that holds potential for understanding faculty uptake and integration. The purpose of the paper is to reveal 
the translation process between teacher beliefs and learning designs for LMS environments, in order to contribute to the conceptual understandings that underpin existing university teacher development approaches for technology integration. A further aim is to provide some insightful stories of the design decisions behind good practices, that may contribute to discussion and reflection on technology use in university education.

This study investigates the beliefs and web practices of three Australian university teachers in order to explore the interrelationship between teacher beliefs and web practices. It investigates how these three teachers believe web technologies such as LMS can be used for university teaching and learning, and how they enact their beliefs through their learning designs in an LMS environment.

\section{The impact of learning management systems}

Increasingly in Australia, North America, the United Kingdom and elsewhere, universities have adopted web based LMS as the technology environment through which a range of pedagogical and administrative tools are offered for university teaching and learning (Coates, James \& Baldwin, 2005). However, many university teachers have difficulty using LMS to create learning designs that are truly engaging to their students. Surveys of students' perceptions of teacher's use of LMS continue to indicate that learners are concerned about the low levels of integration and quality of use in universities (Robbie, 2005; Steel, 2007; University of Denver Center for Teaching \& Learning, 2006; Weaver, Chenicheri \& Spratt, 2005).

As a 'one size fits all' technology solution, it is important to acknowledge that LMS may not be suitable for the expression of all teachers' pedagogies and intentions. LMS are not pedagogically neutral. Some researchers (Apedoe, 2005; Hedberg, 2006; Naidu, 2006) have highlighted the extent to which LMS, in their current form, model structures associated with traditional classroom based activities. Apedoe (2005) explains that LMS were originally conceived by faculty working in higher education who typically drew on teacher centred, transmission models of learning. In Naidu's view (2006), these systems are essentially a page turning tool that encourage passive modes of learning and lack the capability to engage learners in higher level cognitive and social learning. Other researchers have found that they do not easily support the kinds of assessment formats that are well-suited to social constructivist practices, and that they lack a sound structure to efficiently manage student interactions (Papastergiou, 2006).

However research by Holt and Challis (2007) illustrates that a diverse range of pedagogical practices are possible across various disciplines and levels of undergraduate and postgraduate education. Papastergiou (2006) also concedes that there is sufficient evidence that diverse teaching approaches, including behaviourist and constructivist approaches, are possible in LMS environments. Perhaps the pedagogical possibilities are linked to teacher knowledge and expertise. More experienced technology-using teachers may be less constrained by the use of LMS as they are able to work around the technology to express their pedagogical vision. On the other hand, beginner and novice technology-using teachers may be significantly challenged to express their intentions in systems that are pedagogically biased. 
While an evaluation of the pedagogical possibilities of LMS technology is not the major concern of this paper, the affordances and constraints of these technologies are influential. LMS hold different affordances for different teacher beliefs and practices. The notion of affordances (Gibson, 1979; Norman, 1988) is important. It describes the properties or possibilities of an object for action by an actor (in this context the actor is the teacher). While design is about real affordances, it is the actor's perceived affordances that determine usability (Norman, 1998). For example, if teachers do not perceive the technology to be supportive of their pedagogical approach, they may choose not to use it or even use it in ways that are incongruent with their pedagogical beliefs.

It has been suggested that many university teachers require better skills to harness the potential affordances of technologies such as LMS in their teaching (Conole \& Fill, 2005). These kind of explanations may go some way toward explaining why uptake is not nearly as great as anticipated (see Coates et al., 2005; Conole \& Fill, 2005). Affordance theories certainly hold potential for understanding the complex relationships involved in the use of technologies in teaching practices (Day \& Lloyd, 2007). Teachers need to imagine how their pedagogical model will be enacted in a technology environment (Ertmer, 1999; Ertmer et al., 2003). This includes being able to identify the affordances of the technology when they are planning their designs (Webb \& Cox, 2004). Teachers need to see a connection between these affordances and their belief systems.

\section{Teacher beliefs and teacher development}

Teaching is a multi-faceted and multi-layered task that is representative of the personal beliefs of teachers. The concept of 'beliefs' has been used interchangeably with a number of terms such as conceptions, attitudes, implicit and personal theories and cognitive maps (Pajares, 1992). Such ambiguity around the term means it needs to be clearly defined in the context of the research intent and meaning. For this study, a suitable definition is offered by Murphy (2000) who draws on a number of well-known studies (Calderhead, 1986; Clark \& Peterson, 1986; Davis, Konopak \& Readence, 1993; Fox, 1983; Kagan, 1992; Munby, 1982; Pajares, 1992):

\footnotetext{
Teachers' beliefs represent a complex and inter-related system of personal and professional knowledge that serve as implicit theories and cognitive maps for experiencing and responding to reality. Beliefs rely on cognitive and affective components and are often tacitly held. (Murphy, 2000, Ch 3, p.6).
}

Due to the complex and tacit nature of teacher beliefs, they are not readily accessed or understood for their impact on teacher's practices. This is because our belief systems can act as a filter or barrier to change (Yerrick, Parke \& Nugent, 1997). Ertmer and colleagues $(1999 ; 2007)$ characterise barriers to technology integration as external (first order) and internal (second order). While external barriers such as computer access, support and time are relatively easy to identify and resolve, internal barriers such as teacher beliefs about web technologies are more complicated, demanding, and remain a challenging area for academic development.

Revealing the tacit beliefs that underpin successful technology practices and learning designs can provide a powerful stimulus for university teacher development. The use of successful teaching cases has proved a valuable resource in non-technology contexts in both school and university teacher development programs (e.g. Ballantyne, Bain \& 
Packer, 1997; Dunkin, 1995, 2002; Kane, Sandretto, \& Heath, 2004). Real stories of beliefs in practice can also illustrate how certain teaching challenges are overcome and how university teachers reconcile their beliefs about the value of technologies such as LMS.

\section{Purpose of the study}

The purpose of this study is to investigate three cases of successful technology use in order to better understand how teachers reconcile their beliefs to create learning designs for LMS environments. The sample comprises three teachers, Kara, Jack and Tulula, who were recipients of competitive institutional teaching awards at an Australian university. They had also, reportedly, incorporated LMS technologies successfully into their teaching practices. The stories of Kara, Jack and Tulula illuminate their beliefs and the decision-making processes that underpin their learning designs in an LMS environment.

\section{Research questions}

This research questions for the study were:

- How do these university teachers believe web technologies such as LMS can be used effectively in their teaching practices?

- What do they believe to be the role, affordances and limitations of these technologies in terms of their teaching practices?

- How are their beliefs enacted in their learning designs?

A combination of concept mapping and stimulated recall tasks were used in conjunction with interviews to elicit their beliefs and learning designs in an LMS (Blackboard) environment.

\section{Methods}

\section{Sample}

Kara, Jack and Tulula (pseudonyms), were selected purposively from population pools that were representative of similar university teachers using web technologies across the university. Purposive or judgment sampling involves the researcher using their experience and prior knowledge of groups to select participants according to clear criteria (Gay \& Airasian, 2000). Given the research questions, it was important that each teacher held a belief system about the use of web technologies and designed effectively for an LMS learning environment.

These teachers had a range of teaching experiences from five years (Kara), ten years (Jack) and more than fifteen years (Tulula). Kara had been using the web in her teaching practice for all five years, while Jack and Tulula had gained between five and ten years of experience. All teachers held at least one education related degree and were between 36 and 55 years of age. Their disciplinary expertise differed however two identified most closely with arts-humanities and one with science. Kara, Jack and Tulula use web technologies to enhance mixed mode (face to face and distance), face to face and blended forms of teaching respectively. 


\section{Procedure}

The data collection procedure for this study used a combination of stimulated recall, concept mapping and interviews to investigate these university teachers' beliefs and their learning designs for an LMS environment. A pilot study conducted in 2002 concluded that the use of concept mapping and stimulated recall, as data elicitation techniques, were useful in this type of investigation (Steel, 2003).

The first method used, stimulated recall, is designed to access a person's metacognitive knowledge in response to a stimulus (Keith, 1988). Cues that are inherent in the artefact, in this case an LMS website, stimulate the participant to access and verbalize an account of their beliefs, thought processes and ideas in relation to the stimulus (Calderhead, 1981). As the participant was not actually designing or implementing their site during the interview, the teacher was recalling design decisions and student responses retrospectively. It could be argued, that such retrospective verbal reports may not be entirely accurate. There is always some slippage between what one recalls and actuality. This is acknowledged as a limitation of the study. During the stimulated recall task a semi-structured interview with guiding questions prompted each participant to tell the story of their web-based design. They were encouraged to show how it was intended for student learning and evidence their claims. The task was recorded using both audio recording and a screen capture software utility.

The second method, concept mapping, was used to elicit participant's beliefs about the use of web technologies in a learning and teaching context. Concept mapping has been used extensively in educational research and in studies of expert and novice knowledge domains (Olson \& Biolsi, 1991). It provides a medium to represent knowledge structures for varying purposes (Cañas et al., 2003). Concept maps have drawn criticism regarding reliability and validity issues and some researchers have suggested various scoring procedures (e.g. Herl, O'Neil, Chung \& Schacter, 1999; O'Connor \& Johnson, 2004; Taricani \& Clariana, 2006). However, for this study, the purpose was not to rank the maps. They were a means of visualising concepts and interrelationships as advance organisers for interviews on those maps. Thus issues of validity and reliability were secondary to the analysis of their narrative accounts.

Concept maps are usually constructed as open or closed maps. Open maps are those where participants determine their own nodes, concepts and links whereas closed maps are those where participants choose from a finite number of concepts and links to construct their map (Herl et al., 1999). In this study, a blended approach was used. Some pre-printed concepts and linkage words (yellow labels) were provided to the participants to scaffold the activity and facilitate cross-case analysis (Table 1).

Table 1: Pre-printed labels for concept map on beliefs about web technologies

\begin{tabular}{|c|l|l|}
\hline Central concept & \multicolumn{2}{|c|}{ Optional labels } \\
\hline \multirow{4}{*}{$\begin{array}{c}\text { Web } \\
\text { technologies }\end{array}$} & Can (directional arrow) & Cannot (directional arrow) \\
\cline { 2 - 3 } & Role of web technologies & \\
\cline { 2 - 3 } & Effective web technologies & Ineffective web technologies \\
\cline { 2 - 3 } & Effective (web) teaching & Ineffective (web) teaching \\
\cline { 2 - 3 } & Effective (web) learning & Ineffective (web) learning \\
\hline
\end{tabular}


Participants were not compelled to use these and could alter the pre-printed concepts and create their own (green labels). This meant they were encouraged to personalise their maps with concepts that were important to them individually. Kara, Jack and Tulula tended to use the majority of pre-printed labels in addition to their own selfcreated labels. The central concept was web technologies rather than LMS. Although their practice was within an LMS environment, the emphasis was on how teachers believe web technologies can be used educationally and how they resolved these beliefs within an LMS environment.

\section{Data analysis}

As appropriate for a qualitative study such as this one, data analysis comprised an inductive grounded approach where themes and categories of beliefs and practices emerged from the data (Glaser \& Strauss, 1967). Data was constantly reviewed throughout the different stages of data reduction as recommended by Miles and Huberman (1994). Transcripts of stimulated recall interviews were analysed in tandem with viewing the screen capture videos, the archived website and course outlines as required. This assisted in re-examining evidence of participant claims in practice. Transcripts of the concept map interviews were analysed simultaneously with the narrative accounts of participant's beliefs. Early analysis focused on themes and categories that emerged from individual participant data sets. In a cross-case analysis, the data was compared to identify commonalities and differences in participant's beliefs and practices. This included re-clustering and categorising beliefs, perceived affordances and limitations and how these were resolved in the creation of learning designs within an LMS environment.

\section{Results}

Findings indicated that Kara, Jack and Tulula held varied beliefs about how web technologies could be used effectively for teaching and learning and about the roles, affordances and limitations of these technologies. Although these beliefs were enacted in different ways through their learning designs, some important generalisations could be made. To better illustrate some characteristics of their beliefs, sections of their concepts maps are included to illustrate key points for discussion. It should be noted that these have been extracted from the more complex maps and thus do not include all concepts and linkages.

\section{Kara}

\section{Kara's beliefs about web technologies}

In Kara's beliefs about web technologies, several important themes emerge. These concern her beliefs about the attributes of good teaching and how these influence the effectiveness of the web learning environment. For Kara personally, web technologies hold great potential to enact important pedagogical beliefs and resolve some issues around social justice and equity. Kara believes that certain teacher attributes are essential for successful teaching using web technologies. She spoke about these in interview:

My beliefs are that as a teacher you need to be pedagogically aware and obviously have good discipline knowledge. You need to be aware that technologies by themselves are not going to do the job for you. You cannot just use the technologies 
and hope that they going to create a good teaching environment. You, as a teacher, have to take the web technology as a tool, and combine that with your innate educational capabilities to create a learning environment.

This vignette captures Kara's belief about the importance of teachers' pedagogical and disciplinary knowledge. A portion of her concept map (see Figure 1) combines this idea with her belief that teacher knowledge needs to be combined with strong levels of teacher engagement and communication. In fact Kara believes the main limitations of web technologies are teacher knowledge and teachers' reluctance to use the communication facilities to facilitate student learning.

When you have ineffective web teaching and the teacher isn't engaged and isn't involved and communicating, people can hang around waiting. [students] put up a question on the web and can be hanging around for weeks. And by the time that happens, you know a whole raft of things have gone underneath the bridge and they've forgotten and you've forgotten. No learning takes place at all.

She is also cautious that teachers do not take a 'build and they will come' approach to their learning design. Student feedback and input are important to her.

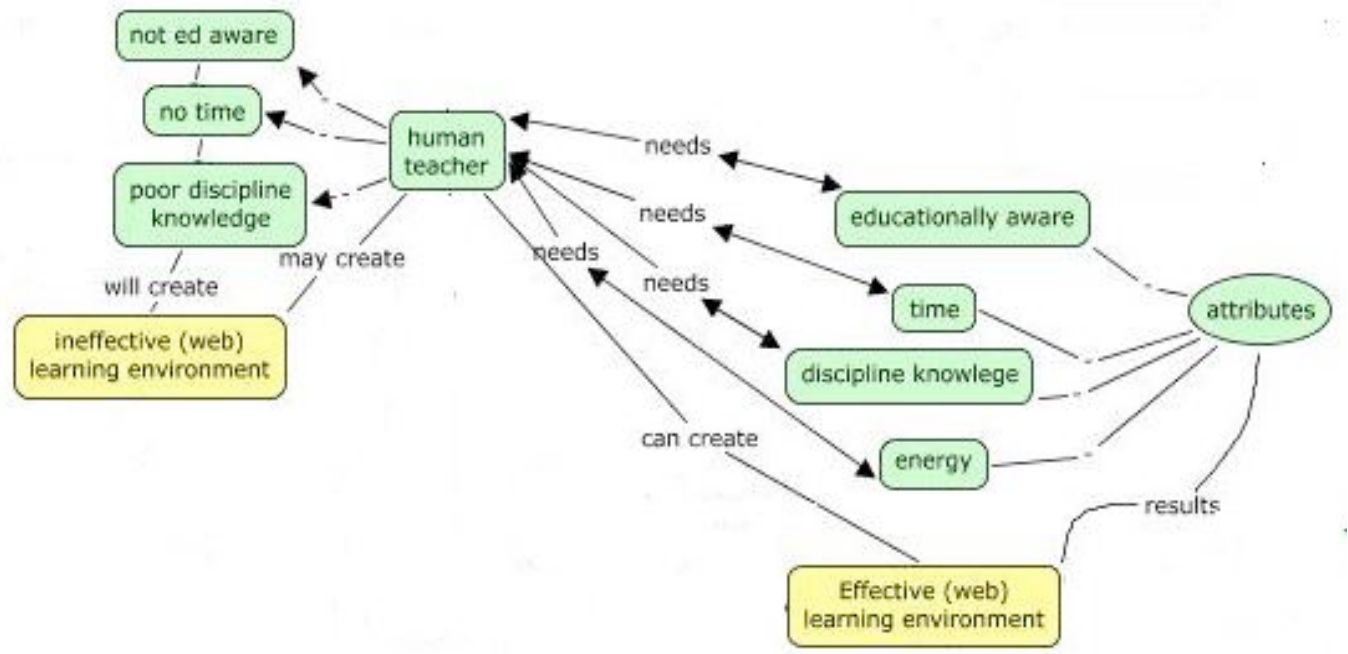

Figure 1: Kara's map: Teacher attributes

As a teacher, Kara feels that web technologies enable her to solve some teaching and learning issues that are close to her heart. Kara's learners are both on and off campus and she has many equity and social justice concerns in relation to their learning experiences. She believes that web technologies like LMS offer her ways of ensuring that both learner cohorts have access to equivalent learning experiences. She feels that communication tools and strategies enable her to promote an inclusive, social and engaging learning environment with strong opportunities for a class culture to emerge. The technologies also offer opportunities for flexibility, reflection and just in time feedback and learning for her students. Additionally, given the non-linear nature of the web, she believes that any web based learning environment is inherently conducive to explorative learning. In her concept map (Figure 2) she illustrates the types of linkages that she thinks need to occur in an effective learning design for this kind of learning environment. 


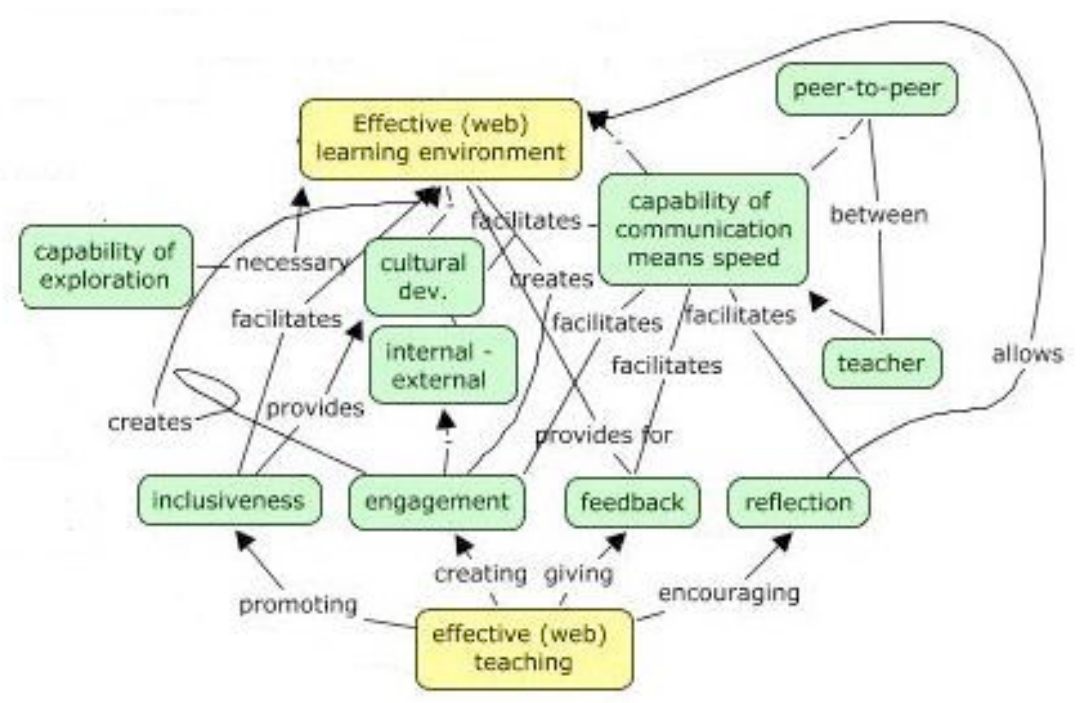

Figure 2: Kara's map: Effective web teaching to create an effective learning environment

Her belief that web technologies offer opportunities for equitable and inclusive learning for her distance learners is discussed at length in interview:

So if they're going be learning at a distance from you, you've got to engage them in the first instance... you have the capability of being inclusive in your teaching. So no one living out there in 'woop woop' land [middle of nowhere], and using web based learning technologies, is on the margins. You make them all part of a course, this is where I say the cultural development comes.

So for Kara, the role of web technologies is to combine their affordances with her own teacher attributes to help her to create an effective learning environment for all her students. The use of web technologies as a communication and socialisation mechanism is a powerful affordance for Kara. Using these tools she feels able to overcome some of her concerns about the traditional disparity in learning experiences that was previously a reality for her distance students. In tandem with the explorative nature of web technologies, these tools offer her many opportunities to engage her learners and develop an inclusive, student centred learning environment.

\section{Kara's practice}

The course website that Kara selected for her stimulated recall interview is one designed for an undergraduate (third year) unit offered in both distance and on campus modes to approximately 50 students. Kara seeks student input into all her learning designs to help her to build a course culture and inform her approach to design.

Kara offers a pedagogical vision for her unit website that resonates strongly with her beliefs. She envisages a learning design that is socially mediated, inclusive and authentic (real world). She explains the approach she uses in all her learning designs. 
Fundamentally the design of my [web based] units is much the same. The idea is to hook in the student, provide interesting content that can be contextualised in real life with a lot of socialisation through communication strategies.

Her rationale for using web technologies is clearly linked with her concern that distance learners have an equitable learning experience and her belief that learning should be socially mediated. Via both an online and face to face orientation, she conveys her expectation of high levels of student participation online to both cohorts of students. While this is often contrary to students' expectations, she reports that after a few weeks students change their approach radically. They realise that participating online regularly is of relevance to their success in completing the unit.

The website incorporates many authentic materials and tasks related to industry based websites. Kara's intention is to 'blend real life with virtual reality'. Industry examples are woven through the online content with hyperlinks to sites where students need to locate and critically evaluate relevant information. The combination of examples and tasks, Kara states, helps to illustrate difficult concepts and encourages students to explore and discover far more about industry than they would learn from content in lectures. She uses communication and socialisation mechanisms (discussion forums) to stimulate change in student thinking and learning approaches. Students are expected to ask content related questions (online) on a regular weekly basis in order to promote reflection and receive just in time feedback. Kara's expectations and philosophy about these discussions are clearly articulated to learners. Discussion board tasks are structured and assessed. Given the voluminous number of postings in the discussion forum it is obvious that Kara's online presence and encouragement contributes to a vibrant interactive learning community. In response to the question 'What do you think the technology has successfully enabled you to do, you couldn't have done otherwise?' Kara replies:

Develop a course culture around students interacting with each other, and with me. I find the students seem to be almost friendlier with me if you like to think about it along those lines. They are at much more ease with me as the lecturer, because I am part of this discussion all the time.

The notions of communication, collaboration and social connectivity are extended to other assessment tasks. Students are given opportunities to work collaboratively on their final task, which entails an industry related scenario. Kara proposes that, as in the real world, students consider the importance of having the right combination of skills (within their team) to realistically complete a professionally oriented task. Student input has an ongoing influence on her design. She asks students to complete a reflective skills portfolio to track what and how students have learned during the unit. This helps her understand how students are using the site and what they find most effective in their learning. The structured discussion forum tasks always come through strongly as an important mechanism for student learning.

In summary, Kara's website characterises her ideas about equity, explorative and socially mediated learning. While she points out that practical elements of learning are not easily addressed in this medium, web technologies help her overcome many challenges and keep her connected with her students via a socially based class culture. Her overall learning design is guided by input from her learners. 


\section{Jack}

\section{Jack's beliefs about web technologies}

Jack believes that his teaching and learning principles represent the overarching ideas that inform his beliefs about web technologies. He emphasises that 'what should drive us are our generic principles about teaching and learning, the objectives behind what we do'. While he is concerned about technology driven use, he does see potential for web technologies to support and extend on campus learning. He also believes that a teacher's pedagogy and objectives should determine whether technologies have any role at all.

Different teaching and learning principles will translate differently in web environments, Jack explains. Personally he does not believe that web technologies are appropriate for a didactic style of teaching. He feels that these technologies are more suitable for supporting active learning and helping teachers engage with their students. In his own case, he identifies great potential to solve some particular teaching and learning issues for his own pedagogical context. He teaches large and diverse classes of on campus students and is troubled by his lack of connection with them during lectures. Web technologies offer him affordances for extending learning beyond the lecture theatre to a safe and more interactive learning space. In this space, he feels students can engage more readily and actively than in large lectures and tutorial classes.

The one thing that has really driven me is to try and engage students in the material.
To move them out of their comfort learning style, i.e. to sit in a lecture room and take
notes and not to ask questions, or be put on the spot. If I have a class of 150 students
and I ask people questions, there are some who cringe, and some who won't be able to
think quickly enough, and some who will try to answer every question. But having
those same questions on a discussion board allows students to participate with an
informed response and without the glare of the other 149 other students if they get it
wrong. So I think the driving force for me was student engagement in the material

It provides opportunities to improve communication among diverse students and with Jack himself. He believes that, in his pedagogical context, such communication enables better reinforcement of theoretical concepts and prospects for meaningful knowledge application. Ultimately that means his students are more actively engaged in their learning and gaining a deeper understanding of the discipline than was possible in traditional lecture-tutorial modes (see Figure 3).

It is the combination of face to face with online learning that Jack sees as powerful for student learning. He loves teaching in front of students because face to face contact gives him a chance to encourage, motivate and enthuse them. Web technologies enable him to extend this learning but he believes they are not enough on their own. Rather, he thinks that teachers need to select the functionality that is relevant to the learning experience they wish to engender.

In particular, Jack is concerned about unwieldy designs that might cause student anxiety and surface learning. He cautions that if teachers don't think through their use technology and their learning designs the site can become a barrier to learning: 


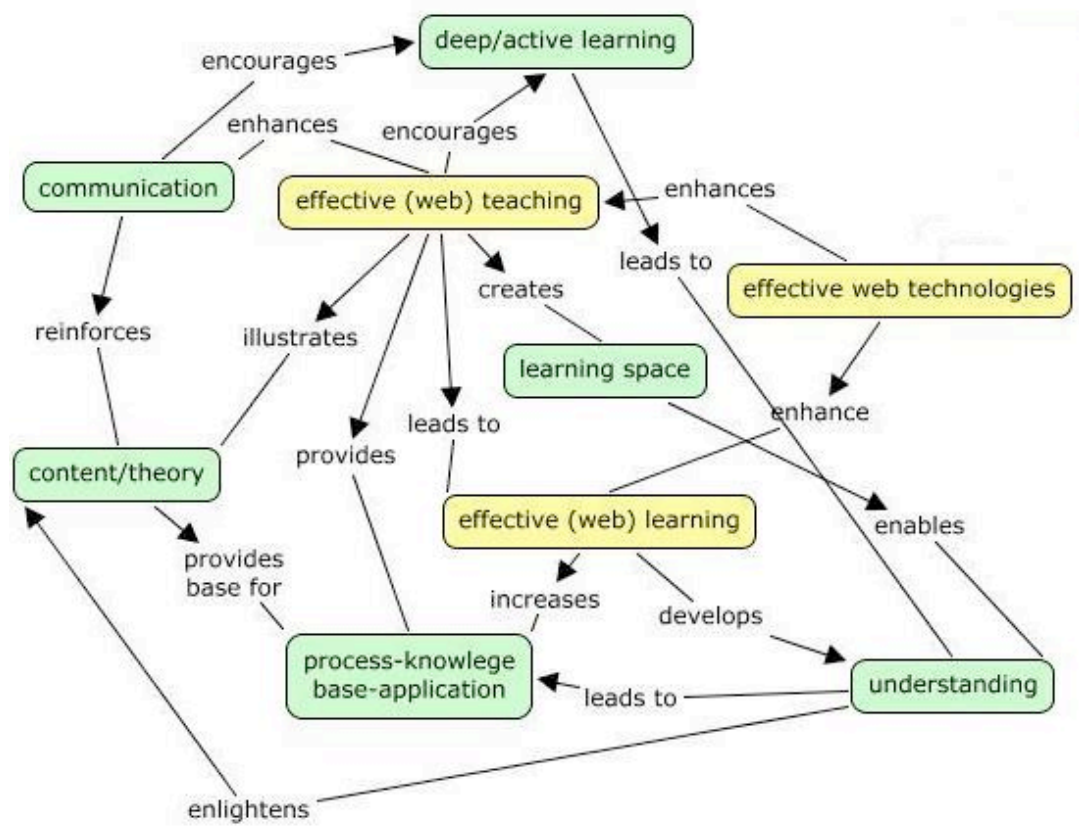

Figure 3: Jack's map: Affordances of web technologies

Ineffective web technology use to me, would be having a core site where you have 4,000 links and no guidance. Students just click. Or that very fancy software with all the bells and whistles - that becomes the focus rather than the learning itself. It diverts attention from learning.

Jack believes the role of web technologies is to support his principles about teaching and learning. In this context, a major affordance is that he can extend on campus student learning to a safe space where students can more actively engage in deeper forms of learning and knowledge application. Jack's major concern is the capacity for technology driven use to confuse students and limit their learning experience.

\section{Jack's practice}

For his stimulated recall task Jack chose a large, first year, on campus undergraduate course with approximately 230 students. There is great diversity amongst Jack's students in terms of age, tertiary entrance scores, family encounters with university and comfort levels with web technologies. For this reason he ensures that students experience a thorough orientation to the website and understand the ways in which he envisages it to be used for learning.

In tutorial in week one, the very first thing they do is to log on. We take them through the web site so they become familiar with the tools, how they are used and how they are accessed. We encourage the younger students who are computer literate, and hopefully have no phobias or anxiety, to use computers so we can engage them. For the mature-age students we are developing their skills and we show them that this particular website is not going to bite them! 
His learning design encapsulates Jack's pedagogical vision for his web enhanced practice, which is to promote active engagement in learning and a disciplinary research culture. It also usefully illustrates his rationale for using web technologies; to provide opportunities for extended, safe and active participation in learning, for this large first year cohort. The use of web based activities encourages students to be more active in their learning in a safe virtual space where they can pose questions without feeling intimidated. It also provides students with ways of bringing to life disciplinary research concepts, applying them and relating that experience back into their on campus learning experience.

Students are given the opportunity to replicate disciplinary theoretical concepts both on and offline. Online tasks use survey, quiz and communication tools to help students to reproduce important research findings that underpin theory. The use of these online tools means that data can be aggregated quickly and then presented in lectures and tutorials for discussion. This makes the research more meaningful and experiential, while stimulating curiosity and promoting understanding. Jack feels he is better connected to students in order to effectively query their decisions and assumptions. Student collaboration, through online role plays, scenario analysis and simulation games, provide opportunities to apply theoretical concepts.

Jack holds the pedagogical belief that through experiential learning students gain a better understanding of theories and concepts. In one of the role play examples, students are given specific roles from various theoretical positions. Jack says that it gives students a chance to 'let their hair down' as it is also quite a humorous activity that students enjoy. Such online activities provide students with the opportunity to participate actively and collaboratively in different ways of learning.

The discussion forum provides a space to exchange views about controversial topics and issues related to the research and theories. Students pose questions and post responses weekly, in tandem with other web based tasks. Jack set an expectation that students engage with the materials before tutorials so they came along already informed and ready to participate. He emphasises that 'we really want our students to become professional thinkers' and the online debates, role plays and discussion forum activities support this ambition as learners could move from 'a kind of personal thinking to a more professional opinion'. Designing such a range of web based activities that are integrated into the face to face components of the course also means that Jack is better able to cater to the diverse range of students that participate in his course. He wants to 'open doors to these students, break myths about university learning and teaching and introduce them to the new frontiers of learning offered by technology'.

In summary, Jack's learning design has a strong interrelationship with his beliefs about web technologies. There is evidence that his use of web technologies is driven by his teaching and learning principles and his desire to engage students differently, deeply, and actively in their learning. Web technologies provide an extended learning space where Jack can connect with his students and encourage them to participate in a research led, experiential learning environment. 


\section{Tulula}

\section{Tulula's beliefs about web technologies}

Tulula's concept map and interview dialogue indicates that she believes there should be strong linkages between her learning design, intended learning outcomes and the role of web technologies. She identifies a range of affordances and limitations around the use of web technologies and believes that good instructional design is critical.

In order to promote effective web based learning, Tulula thinks her students need to understand the linkages between her learning design, their outcomes and the technology used. They also need to see the relevance of their learning to their future professional life (see Figure 4). Importantly, they need to feel socially included, comfortable and motivated during their learning experience. If these kinds of characteristics are part of students' learning experience on the web then it is likely they will learn effectively. Tulula explains:

Effective web learning would be demonstrated by a student who understood the relationship between what they've learnt, using whatever resources and the learning experiences the teacher had presented to them - to the authentic experience - where they're going to need to employ that knowledge.

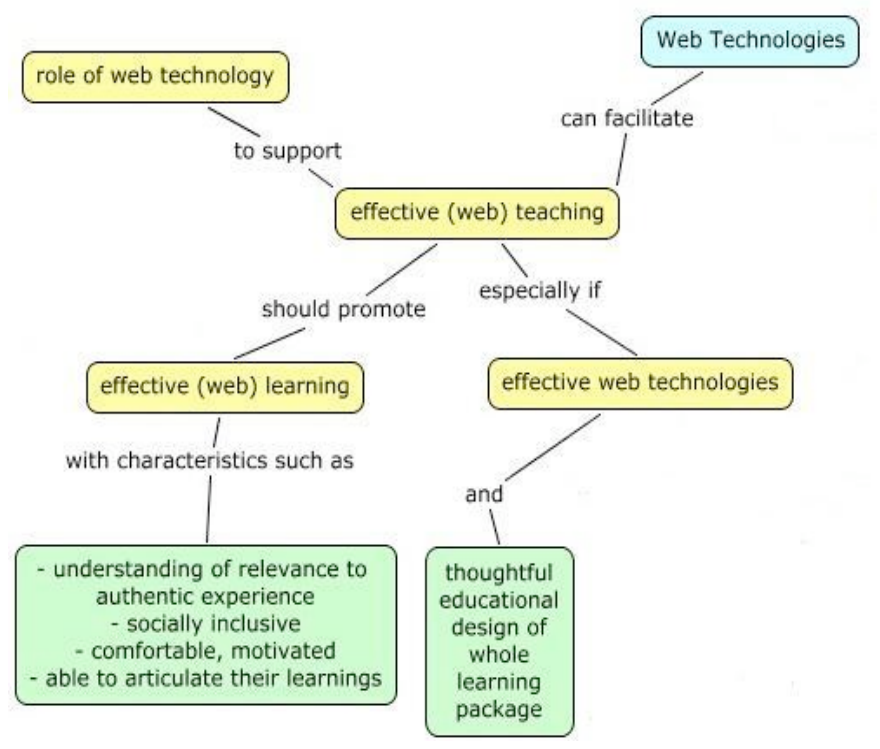

Figure 4: Tulula's map: Effective web learning, teaching and technologies

She cautions that web technologies which facilitate effective teaching and learning look identical to those that promote ineffective teaching and learning. It comes down to the teachers, as designers of the learning experience, specifically thinking about the learning outcomes they want their students to achieve. Tulula is unconvinced that web technologies themselves can be thought of as an entire learning package. She believes they have a range of affordances and limitations that needed to be considered. In her map, she expresses these affordances in terms of what web technologies can and cannot do (see Figure 5). 


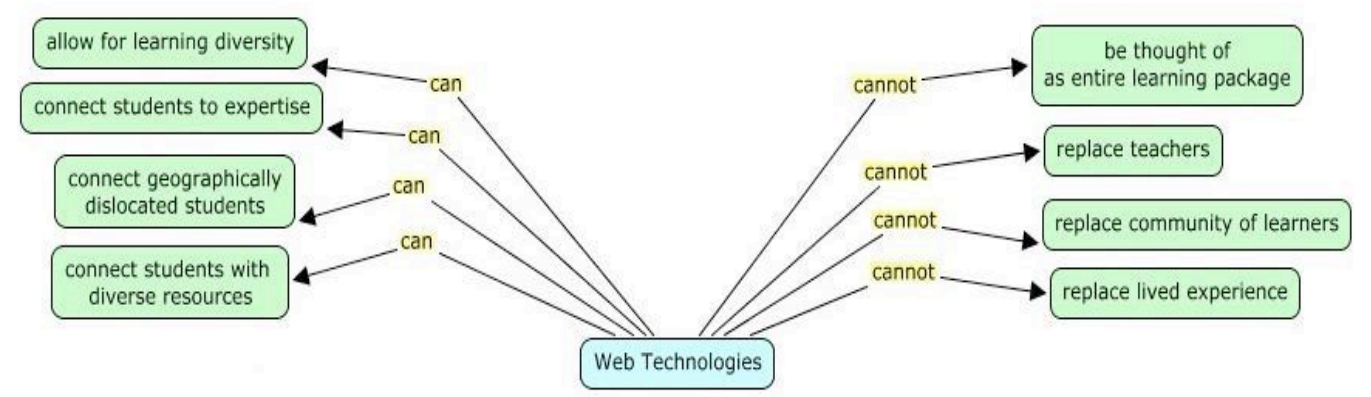

Figure 5: Tulula's map: Affordances and limitations of web technologies

She believes that web technologies can be designed to cater to a range of diverse learning styles and enable multiple ways of connecting students to learning, and their learning community. The concept of social inclusivity is influential to Tulula's thinking. It underpins her belief, 'in the Vygotskian sense', that the most valuable learning takes place when people 'get a chance to predict, to test, and to hear themselves explaining their understandings to others'. For geographically dislocated students, Tulula feels that web technologies provide opportunities to connect with students and help them 'feel welcomed and included'.

Being able to tap into geographically dispersed expertise is a further affordance she identifies. Web technologies can also encourage students to connect to one another's' expertise. This can be facilitated quite easily using web. On the other hand, Tulula also sees a range of limitations of web technologies. In particular, she believes that they cannot replace teachers, communities of learners and the lived experience.

Finally, Tulula emphasises the importance of good quality instructional design. She reinforces this belief in several areas of her concept map (see Figure 6). She points out that 'you can't get beyond a clunky site, that's like a first barrier, if the site doesn't work, then you can't remediate that'. This means that the teacher as designer should be cognisant of learner navigation, effective use of visual and textual media and students' bandwidth access. She also feels that any web components of the learning experience need to be coherent and integrated with offline learning as well as being supportive of the desired learning outcomes.

Ineffective web teaching would be especially likely if the web technologies had a busy visual environment that was incomprehensible and had a high cognitive load for students - too many bangs and whistles and that sort of thing. There's poor linkage of concepts within the web technology and beyond to link the concepts with other resources that are part of your teaching. A poor conceptualisation of how web elements support, compliment, and add value to other learning experiences.

Tulula believes that the quality of use of web technologies is really dependent on the teacher as designer of the learning experience. Learning design should be planned around learning outcomes, and the teacher should consider the affordances, limitations and principles of good instructional design. 


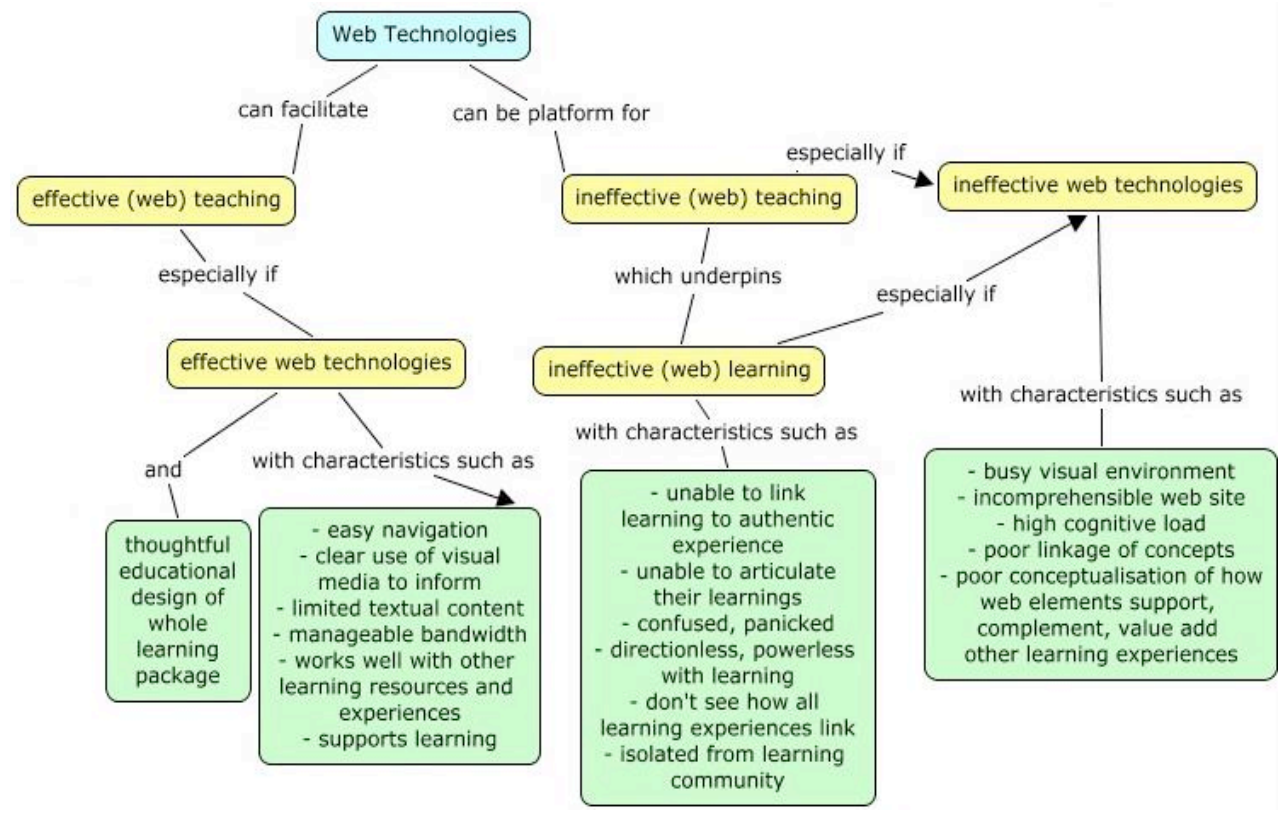

Figure 6: Tulula's map: Instructional design elements

\section{Tulula's practice}

Tulula chose an undergraduate final year unit with between 100 and 150 students for her stimulated recall task. Her pedagogical vision for the website is to connect learning and learner choices to students' future professional lives. Her website is a deliberate blended learning strategy in response to her final year students' preferences around the ways they wish to participate in their learning. These students are reluctant to return to campus for classes after their final practical vocational experience. As these students are about to embark on their professional pathways, Tulula believes that it is essential they make a direct linkage between their practical experience, university learning and their emerging sense of professional self.

A thorough orientation to the website and course is provided both online and in one of the few compulsory on campus components of the course. Although her site is highly complex, it is well-designed and provides students with a diagram and explanation of how the whole unit fits together. Tulula offers students many choices about the professional issues they investigate as part of their learning. Using a highly graphical interface to set the learning context, Tulula's design is professionally framed and invites exploration. It offers students a diverse range of 'adventure' options that are supported by extensive authentic materials. Tulula wants her learners to have 'choices, both in perception and in reality' and hopes that 'the way that [students] learn was going to be matched one way or another, to their preferred learning style' and to their emerging professional interests.

With most students in full time employment and some even working in their profession, Tulula is aware that students need flexibility and choices in the way they participate in learning (both online and offline). As early career professionals, she is concerned that her students can easily become professionally isolated. It is important 
that she try to equip them with tools, strategies, human networks and a sense for how their university learning can be woven into their day to day professional lives.

The idea being to get them to think about the literature and the theory critically in
terms of what they know about [the professional working environment] so that they'd
get this idea, at the very point at which they're going off into the wide world as
professionals, that the university information, knowledge, and resources actually has a
place in getting them through their day to day lives in [their working environment].

These ideas fit easily with Tulula's own pedagogical preferences for authentic learning and experiences. Extensive choices encourage students to engage in authentic experiences and professional discussions. For example, students participate in assessed online debate topics that replicate an 'expert panel' akin to something they would experience in their future working lives. Authentic 'triggers' and 'thought sparks' generate issues orientated, professional online discussions. Tulula believes that by introducing a range of communication based web tools she can provide these new professionals with a 'wonderful opportunity to get professional support' and form support networks. She reports that at the end of the course 'each of the cohorts have set up a discussion board for when they start[their new careers]'. For Tulula this is an 'indices of success' for achieving what she strongly believes to be a core aim of the course - 'What the course hopefully does for the students is it gets them off into the profession with powerful communication tools for the profession'.

In summary, it is evident that Tulula's website design is created specifically to support her teaching and learning aims and pedagogical vision. She uses web technologies as a way of ensuring that students, regardless of their other commitments and geographical location, are able to equitably participate in learning. These technologies help her to be socially inclusive, connect students to each other and diverse resources and expertise. The many learning choices available to students via the site ensure that she caters to learner diversity. Additionally she tries to ensure that her students can see the potential of web technologies as a world wide communication mechanism and resource beyond their university learning.

\section{Discussion}

The purpose of this study is to answer a number of questions about the beliefs and practices of these three university teachers. The first research question was about how these teachers believed that web technologies could be used effectively in their teaching practices. This is addressed through investigating both their beliefs about web technologies and their web enhanced practices. Effective use is interpreted differently by each teacher in the context of their own pedagogical preferences and the teaching and learning issues they specifically wish to solve. There are also important commonalities. All three teachers emphasise that the use of web technologies needs to be derived from an educational need and should certainly not be driven by the technology itself. In corroboration with school based studies by Zhao et al. (2001) and Ertmer et al. (2001), when expressing their beliefs about web technologies, these teachers speak about the technology as a tool to express their pedagogy rather than focusing on the technology itself.

Each teacher conveys a great passion for their subject matter and compassion for their students and their circumstances. There are strong affective components to these teachers' belief systems that demonstrate a commitment to social justice and equity 
through their use of web technologies. They seek to engage and connect with their students and to create inclusive learner communities. Each teacher is very aware of the characteristics of their learner cohorts and of their challenges. They draw on this knowledge as well as their pedagogical knowledge and curriculum objectives to craft learning designs that are supported by their use of web technologies. These learning designs feature a high use of authentic learning approaches and materials and all major online tasks are assessed. Each teacher purposefully draws on principles of instructional design to ensure that there were no unnecessary barriers to learning and that their learning design is coherent and meaningful to students.

The second research question is related to their beliefs about the role, affordances and limitations of these technologies in terms of their teaching practices. It is clear throughout each case that the role of web technologies is to support learning and create an educationally robust learning experience that serves the learning intentions of the designer. The roles ascribed to the technology tools were in servitude to their pedagogical agendas. For the most part, the affordances offered by each participant could be categorised as 'pedagogical affordances' that are selected according to each teacher's pedagogical beliefs and their pedagogical context. For example, Jack envisages extending learning for his large face to face classes by providing a safe online space for communication and participation. Kara's vision is born out of her concern for her distance students feeling isolated, and her need to ensure students are exposed to authentic disciplinary knowledge and skills applied in real contexts. She envisages creating learning experiences that are authentic, socially mediated and provide an equitable and inclusive learning experience for her remote students. Tulula is also concerned about student isolation, particularly for her soon to be early career professionals. She envisages introducing her students to tools and strategies that might reduce this issue and nurture their professional identity in their disciplinary field. She also seeks to provide students with choice and flexibility about how they engage in learning and their learning topics.

Many of the limitations identified are associated with concerns around technologically driven and teacher centred use (mismatch of technology and pedagogy), inappropriate instructional design or circumstances where technologies are an inappropriate solution (e.g. practical experience, lived experience). Jack and Tulula, in particular, are concerned about learners being distracted by too many 'bells and whistles' and they all believe that teachers, as designers, have the greatest influence over the quality of use of technologies in teaching and learning. Collectively they emphasise the necessity for good planning and instructional design to be at the forefront of technology use in education.

The third research question is about how these three teachers enacted their beliefs in their learning designs. Kara, Jack and Tulula clearly draw on their beliefs about the role of web technologies and combine these with their own pedagogical beliefs to form strong pedagogical visions and student focused rationales for using web technologies. The pedagogical affordances and limitations they believe to be inherent in the technology, along with their teaching context, guide how their visions are enacted in their learning designs. These visions are made explicit to students through site orientations, clear instructions, scaffolding and coherent learning designs. Students are encouraged to understand how and why the technologies are being employed and what is expected of them as learners. Active participation, socialisation, communication, collaboration and authentic materials and experiences are key ideas 
and realities across all three web sites and participant belief systems. In different ways, all three teachers seek to provide students with opportunities to create their own knowledge both individually and socially with other students. The notion of connectivity through communication, socialisation and discussion based tasks is present in each learning design.

The interrelationship between these teacher's beliefs and their learning designs is evident in their web practices. As a web technology, the LMS has not impeded the realisation of their pedagogical vision. However in interview, Tulula voiced some frustrations about the limitations of LMS. She drew an analogy of herself as a child in a candy store who was testing the limits and growing impatient as she awaited new possibilities. She said 'It's like being in the lolly shop you know, can I do that?, No you can't do that. But can I do this?' Possibly, due to the strength and coherency of their pedagogical beliefs and beliefs about the value and role of web technologies, each teacher in this study was able to navigate the limitations of an LMS environment and reconcile their beliefs.

However, future studies of the same nature should be conducted with university teachers who are more representative of the academic population and those who are challenged by the use of LMS or do not see a role for such technologies in their university teaching. These kinds of studies would make a valuable contribution to our understanding of technology uptake and use in university teaching and learning. Although workload implications were not specifically investigated as part of this study, workload around the use of technologies in teaching continues to be a contentious factor in Australian universities and is therefore highly likely to be influential to patterns of use and uptake.

Although this study focused on the beliefs and practices of very passionate teachers who were successful in their use of technologies, some important ideas surfaced that may assist less experienced university teachers.

\section{Implications for university teacher development}

Despite the good work of university teacher development units in Australia and other parts of the globe, many university teachers still work in isolation and miss opportunities to share their innovations and practice approaches. Stories such as those of Kara, Jack and Tulula illustrate some of the ways that web technologies such as LMS can be used to promote learning in university classes of varying sizes, modes and learner profiles. They provide important insights into the role of teacher beliefs in the design practices of university teachers using LMS technologies. They also illustrate some of the ways that teachers can translate different teaching approaches into an LMS environment. As stories of practice, these kinds of case studies can be used to gain insights into the design decisions of teachers who use technologies effectively. They can also be used in university teacher development to promote reflection and discourse on the use of technologies in university teaching. Equally, the limitations of web technologies that surface in such discussions are worthy of careful consideration. Technologies are not appropriate for all curriculums, teachers and students.

Through investigating the teacher beliefs that underlie successful models of teacher practice in LMS environments a number of important conceptual implications for university teacher development approaches are uncovered. In order to negotiate these 
technology environments and create effective learning designs, teachers require opportunities to resolve tensions across their own belief systems. This means that teachers need opportunities to articulate their pedagogical beliefs and beliefs about technologies and to negotiate their choices around the use of technologies in their teaching. With reference to their beliefs, teachers need to be encouraged to understand their role as designers and formulate a pedagogical vision for their design with reference to their whole pedagogical context including their own and student characteristics and preferences, the pedagogical approach they wish to employ, the attributes of the learning environment and relevant disciplinary and institutional cultures and norms.

This reconciliation process would be further enabled if teachers are encouraged to identify and discuss the pedagogical affordances and limitations of the technologies available, in relation to their own pedagogical beliefs, vision and context. This kind of personal reflection needs to be incorporated more fully into informal teacher development approaches as well as formal programs such as Graduate Certificates of Higher Education. However, the velocity of change in the affordances offered by learning technologies presents a significant challenge as does the minimal incentives available to university teachers to use technologies effectively in their teaching practices.

\section{Acknowledgments}

The author would like to thank the following people for their thoughtful feedback on this paper: Professor Mike Levy and Professor Joy Cummings (Griffith University), Dr Catherine Manathunga (University of Queensland), and Dr Kim McShane (University of California, Santa Barbara).

\section{References}

Apedoe, X. (2005). The interplay of teaching conceptions and course management system design: Research implications and creative innovations for future designs. In A. Jafari \& P. McGee (Eds.), Course management systems for learning: Beyond accidental pedagogy (pp. 57-68). Hershey PA: Information Science

Bain, J. D., McNaught, C., Lueckenhausen, G. \& Mills, C. (1998). Describing computer-facilitated learning environments in higher education. Learning Environments Research, 1(2), 163-180.

Ballantyne, R., Bain, J. D. \& Packer, J. (1997). Reflecting on university teaching: Academics' stories. Canberra: Australian Government Publishing Service.

Calderhead, J. (1981). Stimulated recall: A method for research on teaching. British Journal of Educational Psychology, 51, 211-217

Calderhead, J. (1986). Teacher beliefs and knowledge. In D. Berliner \& R. Clafee (Eds.), Handbook of educational psychology (pp. 709-725). New York: Simon \& Shuster MacMillan

Cañas, A. J., Coffey, J. W., Carnot, M. J., Feltovich, P., Hoffman, R. R., Feltovich, J., et al. (2003). A summary of literature pertaining to the use of concept mapping techniques and technologies for education and performance support. Prepared for The Chief of Naval Education and Training, Pensacola FL. http: / / www.ihmc.us/users / acanas / Publications / ConceptMapLitReview / IHMC\%20Literature\%20Review\%20on\%20Concept\%20Mapping.pdf

Clark, C. M. \& Peterson, P. L. (1986). Teachers' thought processes. In M. Wittrock (Ed.), Handbook of research on teaching (pp. 255-296). New York: Macmillan 
Coates, H., James, R. \& Baldwin, G. (2005). A critical examination of the effects of learning management systems on university teaching and learning. Tertiary Education and Management, 11, 19-36

Conole, G. \& Fill, K. (2005). A learning design toolkit to create pedagogically effective learning activities. Journal of Interactive Media in Education, 2005(8). http: / / wwwjime.open.ac.uk/2005/08/ conole-2005-08-paper.html

Davis, M. M., Konopak, B. C. \& Readence, J. E. (1993). An investigation of two chapter 1 teacher's beliefs about reading and instructional practices. Reading Research and Instruction, $33,105-133$.

Day, D. \& Lloyd, M. (2007). Affordances of online technologies: More than the properties of the technology. Australian Educational Computing, 22(2), 17-21. http:/ / www.acce.edu.au/uploads/documents/store/resources/res_1124_AEC_vol22_2_2007.pdf

Dunkin, M. J. (1995). Concepts of teaching and teaching excellence in higher education. Higher Education Research and Development, 14, 21-33

Dunkin, M. J. (2002). Novice and award-winning teachers' concepts and beliefs about teaching in higher education. In N. Hativa \& P. Goodyear (Eds.), Teacher thinking, beliefs and knowledge in higher education. Dordrecht: The Netherlands: Kluwer Academic Publishers

Ertmer, P. (1999). Addressing first- and second-order barriers to change: Strategies for technology integration. Educational Technology, Research and Development, 47(4), 47-61.

Ertmer, P., Conklin, D., Lewandowski, J., Osika, E., Selo, M. \& Wignall, E. (2003). Increasing preservice teachers' capacity for technology integration through the use of electronic models. Teacher Education Quarterly, 30(1), 95-112.

Ertmer, P. A., Addison, P., Lane, M., Ross, E. \& Woods, D. (1999). Examining teachers' beliefs about the role of technology in the elementary classroom. Journal of Research on Computing in Education, 32, 54-72.

Ertmer, P. A., Ottenbreit-Leftwich, A. \& York, C. S. (2006-2007). Exemplary technology-using teachers: Perceptions of factors influencing success. Journal of Computing in Teacher Education, 23(2), 55-61.

Fox, D. (1983). Personal theories of teaching. Studies in Higher Education, 8(2), 151-163

Gay, L. R. \& Airasian, P. (2000). Educational research competencies for analysis and application (6th ed.). New Jersey: Prentice Hall.

Gibson, J. J. (1979). The ecological approach to visual perception. Boston: Houghton Mifflin.

Glaser, B. G. \& Strauss, A. L. (1967). The discovery of grounded theory. Chicago: Aldine.

Gow, L. \& Kember, D. (1993). Conceptions of teaching and their relationship to student learning. British Journal of Educational Psychology, 63, 20-33.

Hativa, N. \& Goodyear, P. (2002). Research on teacher thinking, beliefs, and knowledge in higher education: Foundations, status and prospects. In N. Hativa \& P. Goodyear (Eds.), Teacher thinking, beliefs and knowledge in higher education. Dordrecht: The Netherlands: Kluwer Academic Publishers.

Hedberg, J. G. (2006). E-learning futures? Speculations for a time yet to come. Studies in Continuing Education, 28(2), 171-183.

Herl, H. E., O'Neil, H. F., Chung, G. K. W. K. \& Schacter, J. (1999). Reliability and validity of a computer-based knowledge mapping system to measure content understanding. Computers in Human Behavour, 15, 315-333.

Holt, D. \& Challis, D. (2007). From policy to practice: One university's experience of implementing strategic change through wholly online teaching and learning. Australasian Journal of Educational Technology, 23(1), 110-131. http: / / www.ascilite.org.au/ajet/ajet23/holt.html 
Kagan, D. M. (1992). Implications of research on teacher belief. Educational Psychologist, 27(1), 6590.

Kane, R., Sandretto, S. \& Heath, C. (2002). Telling half the story: A critical review of research on the teaching beliefs and practices of university academics. Review of Educational Research, 72(2), 177-228.

Kane, R., Sandretto, S. \& Heath, C. (2004). An investigation into excellent tertiary teaching: Emphasising reflective practice. Higher Education, 47(3), 283-310.

Keith, M. J. (1988). Stimulated recall and teacher's thought processes: A critical review of the methodology and an alternative perspective. Paper presented at the Annual Meeting of the Mid-South Educational Research Association, Louisville, Kentucky.

Kember, D. (1997). A reconceptualisation of the research into university academics' conceptions of teaching. Learning and Instruction, 7(3), 255-275.

Mahdizadeh, H., Biemans, H. \& Mulder, M. (2008). Determining factors of the use of e-learning environments by university teachers. Computers $\mathcal{E}$ Education, 51(1), 142-154.

Miles, M. B., \& Huberman, A. M. (1994). Qualitative data analysis: An expanded sourcebook (2nd ed.). Thousand Oaks: Sage Publications.

Miller, S., Meier, E., Payne-Bourcy, L., Shablak, S., Newmann, D. L., Wan, T. Y., et al. (2003). Technology use as a catalyst for change: A leadership framework for transforming urban teacher preparation. International Electronic Journal for Leadership in Learning, 7(12). http: / / www.ucalgary.ca/iejll/miller_et_al

Munby, H. (1982). The place of teachers' beliefs in research on teacher thinking and decision making, and an alternative methodology. Instructional Science, 11, 201-225.

Murphy, E. (2000). Strangers in a strange land: Teachers' beliefs about teaching and learning French as a second or foreign language in online learning environments. Unpublished $\mathrm{PhD}$, Université Laval, Quebec. [verified 12 July 2009] http:/ / www.nald.ca/fulltext/stranger/cover.htm

Naidu, S. (2006). E-Learning: A guidebook of principles, procedures and practices (2nd ed.). New Delhi: Commonwealth Educational Media Center for Asia. http: / /www.cemca.org/elearning_guidebook.pdf See also http:/ / www.wikieducator.org/WikiEdProfessional_eLearning_Guidebook

Norman, D. A. (1988). The psychology of everyday things. New York: Basic Books.

Norman, D. A. (1998). The invisible computer. Cambridge: MIT Press.

O'Connor, D. L. \& Johnson, T. E. (2004). Measuring team cognition: Concept mapping elicitation as a means of constructing team shared mental models in an applied setting. Paper presented at the First International Conference on Concept Mapping, Pamplona, Spain.

Olson, J. R. \& Biolsi, K. J. (1991). Techniques for representing expert knowledge. In K. A. Ericsson \& J. Smith (Eds.), Toward a general theory of expertise: Prospects and limits. Cambridge: Cambridge University Press.

Pajares, F. (1992). Teachers' beliefs and educational research: Cleaning up a messy construct. Review of Educational Research, 62(3), 307-332.

Papastergiou, M. (2006). Course management systems as tools for the creation of online learning environments: Evaluation from a social constructivist perspective and implications for their design. International Journal on ELearning, 5(4), 593-622.

Park, S. H. \& Ertmer, P. A. (2007). Impact of problem-based learning (PBL) on teachers' beliefs regarding technology use. Journal of Research on Technology in Education, 40(2), 247-267.

Reeves, T. C. \& Reeves, P. M. (1997). Effective dimensions of interactive learning on the world wide web. In B. H. Khan (Ed.), Web-based instruction (pp. 59-66). Englewood Cliffs, NJ: Educational Technology Publications.

Robbie, D. (2005). Students use and experiences of Bb at Swinburne: A longitudinal study 20012005. Paper presented at the Blackboard Asia Pacific Users Conference, Melbourne. 
Samuelowicz, K. \& Bain, J. D. (1992). Conceptions of teaching and learning held by academic teachers. Higher Education, 24, 93-111.

Steel, C. H. (2003). Investigating concept mapping and stimulated recall to reveal academic teacher beliefs and how they are enacted through learning designs for the web. In D. Lassner \& C. McNaught (Eds.), Proceedings of World Conference on Educational Multimedia, Hypermedia and Telecommunications 2003 (pp. 2217-2224). Chesapeake, VA: AACE. [verified 17 Jul 2009] http: / / espace.library.uq.edu.au/view/UQ:99757

Steel, C. H. (2007). What do university students expect from teachers using an LMS? In ICT: Providing choices for learners and learning. Proceedings ascilite Singapore 2007. (pp. 942-950). Singapore: Nanyang Technical University. http: / / www.ascilite.org.au/conferences/singapore07/ procs/steel.pdf

Taricani, E. M. \& Clariana, R. B. (2006). A technique for automatically scoring open-ended concept maps. Educational Technology, Research and Development, 54(1), 65-82

University of Denver Center for Teaching \& Learning (2006). Blackboard student survey report. Denver: University of Denver. http: / / ctl.du.edu/ support/ blackboard / BbStudentReportWinter06.pdf

Veen, W. (1993). The role of beliefs in the use of information technology: Implication for teacher education, or teaching the right thing at the right time. Technology, Pedagogy and Education, 2(2), 139-153.

Weaver, D., Chenicheri, S. N. \& Spratt, C. (2005). Evaluation: WebCT and the student experience. Paper presented at Making a difference: 2005 Evaluations and Assessment Conference, Sydney. [verified 12 July 2009] http:/ / www.iml.uts.edu.au/EAC2005/papers/Weaver.html

Webb, M. \& Cox, M. (2004). A review of pedagogy related to information and communication technology. Technology, Pedagogy and Education, 13(3), 235-286.

Yerrick, R., Parke, H. \& Nugent, J. (1997). Struggling to promote deeply rooted change: The "Filtering Effect" of teachers' beliefs on understanding transformational views of teaching science. Science Education, 81, 137-159.

Zhao, Y. \& Frank, K. A. (2003). Factors affecting technology uses in schools: An ecological perspective. American Educational Research Journal, 40(4), 807-840.

Zhou, G. \& Xu, J. (2007). Adoption of educational technology ten years after setting strategic goals: A Canadian university case study. Australasian Journal of Educational Technology, 23(4), 508-528. http:/ / www.ascilite.org.au/ajet/ ajet23/zhou.html

Dr Caroline Steel, Teaching and Education Development Institute,

The University of Queensland, Brisbane QLD 4072 Australia.

Email: c.steel@uq.edu.au

Web: http:/ / www.uq.edu.au/uqresearchers/ researcher/steelch.html

Please cite as: Steel, C. (2009). Reconciling university teacher beliefs to create learning designs for LMS environments. Australasian Journal of Educational Technology, 25(3), 399-420. http: / / www.ascilite.org.au/ajet/ ajet25/steel.html 